\title{
Adult respiratory distress syndrome and pancytopenia associated with miliary tuberculosis in a HIV-infected patient
}

\author{
A. Mofredj, J.M. Guerin, F. Leibinger, R. Masmoudi
}

\begin{abstract}
Adult respiratory distress syndrome and pancytopenia associated with miliary tuberculosis in a HIV-infected patient. A. Mofredj, J.M. Guerin, F. Leibinger, R. Masmoudi. COERS Journals 1996.

ABSTRACT: Adult respiratory distress syndrome (ARDS) is a rare but severe complication of miliary tuberculosis, which may appear even after introduction of antituberculosis therapy. Mortality has been reported to be as high as $100 \%$ if there is associated pancytopenia.

We report a case of a patient infected with the human immunodeficiency virus who presented with miliary tuberculosis associated with pancytopenia and adult respiratory distress syndrome.

Eur Respir J., 1996, 9, 2685-2687.
\end{abstract}

Service de Réanimation Médicale, Hôpital Lariboisière, 2, rue Ambroise Paré, 75010, Paris, France

Correspondence: A. Mofredj,

Service de Réanimation Médicale,

Hôpital Lariboisière, 2, rue Ambroise Paré, 75010 Paris, France

Keywords: Adult respiratory distress syndrome, human immunodeficiency virus, miliary tuberculosis, pancytopenia

Received: April 41996

Accepted after revision June 251996
A heterogenous group of diseases leading to direct and indirect pulmonary injury may be associated with adult respiratory distress syndrome (ARDS). Its occurrence during miliary tuberculosis, although unusual, is well-documented $[1,2]$. In some cases, this syndrome appears within a few days after initiation of antituberculosis therapy [3]. Its association with pancytopenia, itself an unusual complication of disseminated tuberculosis [1], is rare but leads to an extremely poor prognosis. We present a case of a human immunodeficiency virus (HIV)-infected patient who developed ARDS and pancytopenia as complications of miliary tuberculosis.

\section{Case report}

A 38 year old woman native of Ghana presented to the emergency room because of shortness of breath, tiredness and weight loss.

The patient had been well until 5 months earlier, when she complained about diarrhoea and weight loss. No obvious reason for the diarrhoea was found but a HIVtest turned out to be positive. She was then lost to follow-up.

On examination, the patient was profoundly ill. Her temperature was $39.4^{\circ} \mathrm{C}$, pulse 150 beats $\cdot \mathrm{min}^{-1}$, respiratory rate 35 breaths $\cdot \mathrm{min}^{-1}$ and blood pressure $140 / 100$ $\mathrm{mmHg}$. Cardiovascular and pulmonary examination was normal. Laboratory findings were: creatinine 0.22 $\mathrm{mmol} \cdot \mathrm{L}^{-1}$; urea nitrogen $15.8 \mathrm{mmol} \cdot \mathrm{L}^{-1}$; potassium 2 $\mathrm{mmol} \cdot \mathrm{L}^{-1}$; alanine aminotransferase, $85 \mathrm{IU} \cdot \mathrm{L}^{-1}$; aspartate aminotransferase $209 \mathrm{IU} \cdot \mathrm{L}^{-1}$; alkaline phosphatase 235 IU. $\mathrm{L}^{-1}$; and pancytopenia. Blood gas analysis while breathing $3 \mathrm{~L} \cdot \mathrm{min}^{-1}$ of oxygen showed: $\mathrm{pH}, 7.43$; arterial carbon dioxide tension $\left(\mathrm{Pa}_{\mathrm{a}} \mathrm{CO}_{2}\right) 2.6 \mathrm{kPa}$ and arterial oxygen tension $\mathrm{Pa}_{\mathrm{a}} \mathrm{O}_{2}, 13.5 \mathrm{kPa}$. Chest radiographic studies showed disseminated micronodular opacities. The patient was admitted to the intensive care unit.

On the second day of hospitalization, the patient appeared to be critically ill. She had respiratory distress and needed mechanical ventilatory support. Chest radiographic studies revealed extension of the micronodular opacities with several areas of pulmonary consolidation. The $\mathrm{Pa}, \mathrm{O}_{2}$ at an inspired oxygen fraction $\left(F \mathrm{I}, \mathrm{O}_{2}\right)$ of 0.4 was $27.7 \mathrm{kPa}$. Bronchoalveolar lavage (BAL) was performed.

On the third day of hospitalization, antituberculosis treatment (isoniazid, ethambutol, rifampicin and pyrazinamide) was initiated because BAL examination revealed multiple acid-fast bacilli (AFB). No other infectious agent was found. Bone marrow biopsy showed a marked hypocellularity but no granulomata.

A few hours after initiation of treatment, the patient collapsed and needed inotropic support. She became comatose with a Glasgow score of 4 (eye opening 1;

Table 1. - Haematological findings

\begin{tabular}{lrrrr}
\hline & \multicolumn{4}{c}{ Hospital days } \\
& 1st & 2nd & 3rd & 4th \\
\hline Haemoglobin $g \cdot \mathrm{dL}^{-1}$ & 8.6 & 6.0 & 9.3 & 8.3 \\
Haematocrit \% & 25 & 22 & 27 & 24 \\
Platelets $\times 10^{9} \cdot \mathrm{L}^{-1}$ & 93 & 34 & 36 & 18 \\
WBC $\times 10^{9} \cdot \mathrm{L}^{-1}$ & 2.2 & 2.2 & 1.8 & 2.0 \\
Neutrophils $\times 10^{6} \cdot \mathrm{L}^{-1}$ & & 1980 & 1640 & \\
Lymphocytes $\times 10^{6} \cdot \mathrm{L}^{-1}$ & & 220 & 110 & \\
Reticulocytes \% & & & & 1 \\
\hline
\end{tabular}

WBC: white blood cell count. 
vocal response 1 ; motor response 2 ). Laboratory findings showed increasing pancytopenia with marked lymphopenia (table 1). Arterial blood gas studies while the patient was ventilated with an $F_{\mathrm{I}}, \mathrm{O}_{2}$ of 1 showed: $\mathrm{pH}$ 7.02; $\mathrm{Pa}, \mathrm{CO}_{2} 6.4 \mathrm{kPa}$ and $P \mathrm{a}, \mathrm{O}_{2} 15.7 \mathrm{kPa}$. Repeated chest radiographic studies showed bilateral pulmonary consolidation. Intravenous methylprednisolone $\left(3 \mathrm{mg} \cdot \mathrm{kg}^{-1}\right.$ daily) was added to the regimen.

In the following days, the patient's condition worsened in spite of treatment. Laboratory and chest radiographic studies were unchanged. Physical examination showed the development of abdominal distension with ascitis. Chemical analysis of the fluid showed: albumin $17 \mathrm{~g} \cdot \mathrm{L}^{-1}$ and glucose $10.6 \mathrm{mmol} \cdot \mathrm{L}^{-1}$. The patient died on the eighth day, with evidence of multiple organ failure. Mycobacterial cultures of ascitis, BAL and bone marrow were positive for Mycobacterium tuberculosis, which was susceptible to the regimen. Serological studies were negative for parvovirus B 19, cytomegalovirus and hepatitis B, C and D virus. No autopsy was performed.

\section{Discussion}

Miliary tuberculosis is an unusual cause of ARDS [1, 2]. MarteEns et al. [1] found that less than 7\% of cases of miliary tuberculosis are associated with this syndrome. In these cases, the duration of symptoms before development of ARDS is generally longer than in other infections $[1,4,5]$. However, the progression of the pulmonary process may be fulminant [6-8] causing clinicians to underestimate the possibility of miliary tuberculosis in the differential diagnosis. In addition, there are several factors giving rise to an increased risk of delayed diagnosis: before development of ARDS, chest radiographs often fail to show the typical miliary pattern and examination of bronchial secretions is often negative for Mycobacterium tuberculosis [5]. In almost all cases of miliary tuberculosis with ARDS the tuberculin test was negative, whereas it was positive in $60-80 \%$ of patients with noncomplicated miliary tuberculosis [4].

Concerning ARDS in general, the pathogenesis of ARDS during disseminated tuberculosis is not well understood. Since pathological findings are similar to those found in cases of ARDS due to other infectious causes, mechanisms may be the same as in the general physiopathological pathway of ARDS. Recently, it has been speculated that mycobacterial products may behave in vivo like bacterial lipopolysaccharide [5]. Among these, lipoarabinomannan has been shown to induce the production of tumour necrosis factor (TNF) in human macrophages, which might contribute to the development of ARDS [5]. The fact, that ARDS often develops within a few days after initiation of antibiotic treatment [3] suggests that lytic antibacterial therapy may participate in the initiation of this process.

Even with adequate therapy, mortality in ARDS related to disseminated tuberculosis has been reported to be as high as $100 \%$. Other underlying diseases, delayed diagnosis and the appearance of further complications, such as disseminated intravascular coagulation, septic shock or pancytopenia, are additional factors of poor prognosis [4].
Haematological abnormalities are common and multiple in patients with acquired immune deficiency syndrome (AIDS) and the occurrence of pancytopenia is frequent. The causes of these changes are various and often associated with other factors, including infection by the human immunodeficiency virus (HIV) itself, drug reaction, infiltrative disease of the bone marrow and opportunistic infections [9]. In the present case, the presence of AFB in the bone marrow strongly suggests a key role of Mycobacterium tuberculosis in the mechanisms leading to pancytopenia. However, we cannot rule out the possibility that pancytopenia in this AIDS patient has been aggravated by advanced HIV disease. To our knowledge, the frequency of pancytopenia during disseminated tuberculosis in HIV-infected patients has never been evaluated.

In the nonimmunocompromised population, miliary tuberculosis has been shown to be associated with bone marrow involvement and haematological abnormalities, and several reports have focused on the occurrence of pancytopenia $[1,10]$. However, this complication appears to be extremely rare $[1,10]$, with an incidence of less than $6 \%$ of all cases of miliary tuberculosis [1], but if present, it is a factor of poor prognosis.

Pancytopenia might be explained by bone marrow suppression secondary to an immune-mediated mechanism [1] and/or to extensive necrotizing granulomata of the bone marrow. Recently, it was suggested that TNF might contribute not only to the development of ARDS but also to a decrease of haematopoiesis and, thus, explain, as in our patient, concomitant pancytopenia [5].

However, current knowledge about the immunological changes induced by Mycobacterium tuberculosis infection is insufficient to explain the development of eventual complications such as ARDS, pancytopenia, disseminated intravascular coagulation (DIC) and hepatitis. Further research will, thus, be necessary to develop a coherent hypothesis about the pathogenesis of these complications.

Hepatitis has been reported to be one of the major features of disseminated tuberculosis. Granulomata are found in liver biopsy, with a frequency as high as $88 \%$ [1]. Because serological studies for hepatitis B, C and $\mathrm{D}$ virus and cytomegalovirus were negative, we concluded that in our patient hepatitis was due to disseminated tuberculosis. However, liver biopsy could not be performed because of profound thrombopenia.

The concomitant association of both ARDS and pancytopenia with disseminated tuberculosis is rare. In a review of the recent literature, we found only eight cases where all patients died despite antituberculosis treatment [2, 5-8]. However, if this association is present, clinicians should be aware of the possible diagnosis of disseminated tuberculosis, especially in HIV-infected patients who are susceptible to severe forms of the disease [11]. In addition to repeated tracheobronchial smears, bone marrow biopsy, rather than simple aspiration, and liver biopsy are suitable to establish the diagnosis [1]. Intravenous preparations of antituberculosis drugs should be given early [11].

During the progression of acute lung injury, pretreatment with anti-inflammatory agents has been shown to substantially decrease not only pulmonary hypertension and arterial hypoxaemia but also the release of specific 
components of the inflammatory cascade, including tumour necrosis factor [12]. Since these mediators are likely to play a key role in the development of adult respiratory distress syndrome in miliary tuberculosis, and are possibly produced at high levels after introduction of antituberculosis therapy, early pretreatment with corticosteroids may improve the outcome of patients with disseminated tuberculosis.

\section{References}

1. Marteens G, Willcox PA, Benatar SR. Miliary tuberculosis: rapid diagnosis, hematologic abnormalities, and outcome in 109 treated adults. Am J Med 1990; 89: 291-296.

2. Piqueras AR, Marruecos L, Artigas A, Rodriguez C. Miliary tuberculosis and adult respiratory distress syndrome. Intensive Care Med 1987; 13: 175-182.

3. Onwubalili JK, Scott GM, Smith H. Acute respiratory distress related to chemotherapy of advanced pulmonary tuberculosis: a study of two cases and review of the literature. $Q J$ Med 1986; 59: 599-610.

4. Roger PM, Deloffre P, Tiger F, et al. Prognosis of adult respiratory distress syndrome in tuberculosis patients: 4 case reports. Presse Méd 1995; 24: 1021-1024.
5. Benatar SR, McLoud TC, Mark EJ. Case 23, 1995: case records of the Massachusetts General Hospital. N Engl J Med 1995; 333: 241-248.

6. Baziz A, Clément C, Perdrix C, Coiffic A. Miliary tuberculosis associated to respiratory distress syndrome: a report of two cases. Ann Med Interne 1995; 146: 123125.

7. Colbert N, Lemaire F, Trunet P, Carlet J, Lange F, Rapin M. A rare cause of acute respiratory distress syndrome in adults: acute disseminated pulmonary tuberculosis. Four cases. Nouv Presse Méd 1981; 10: 3049-3052.

8. Chapalain JC, Escarment J, Garin D, et al. Acute respiratory distress syndrome due to Mycobacterium tuberculosis. Méd Mal Infect 1993; 23: 46-48.

9. Scadden DT, Li Z, Groopman JE. Pathophysiology and management of HIV-associated hematologic disorders. Blood 1989; 74: 1455-1463.

10. Lombard EH, Mansvelt EPG. Haematological changes associated with miliary tuberculosis of the bone marrow. Tubercle 1993; 74: 131-135.

11. Gachot B, Wolff M, Clair B, Régnier B. Severe tuberculosis in patients with human immunodeficiency virus infection. Intensive Care Med 1990; 16: 491-493.

12. Metz C, Sibbald WJ. Anti-inflammatory therapy for acute lung injury: a review of animal and clinical studies. Chest 1991; 100: 1110-1119. 